\title{
Correction to: Physical Virology
}

\author{
Urs F. Greber
}

\section{Correction to:}

U. F. Greber (ed.), Physical Virology, Advances in Experimental Medicine and Biology 1215, https://doi.org/10.1007/978-3-030-14741-9

This book was unfortunately published with a wrong volume number 1140 . The correct volume number is 1215 .

The book has been corrected now. 